\title{
Characterization of NMC Lithium-ion Battery Degradation for Improved Online State Estimation
}

Thingvad, Malthe; Calearo, Lisa; Thingvad, Andreas; Viskinde, Rasmus; Marinelli, Mattia

Published in:

Proceedings of the $55<$ sup $>$ th $</$ sup $>$ International Universities Power Engineering Conference 2020

Link to article, DOI:

10.1109/UPEC49904.2020.9209879

Publication date:

2020

Document Version

Peer reviewed version

Link back to DTU Orbit

Citation (APA):

Thingvad, M., Calearo, L., Thingvad, A., Viskinde, R., \& Marinelli, M. (2020). Characterization of NMC Lithiumion Battery Degradation for Improved Online State Estimation. In Proceedings of the 55 International Universities Power Engineering Conference 2020 IEEE. https://doi.org/10.1109/UPEC49904.2020.9209879

\section{General rights}

Copyright and moral rights for the publications made accessible in the public portal are retained by the authors and/or other copyright owners and it is a condition of accessing publications that users recognise and abide by the legal requirements associated with these rights.

- Users may download and print one copy of any publication from the public portal for the purpose of private study or research.

- You may not further distribute the material or use it for any profit-making activity or commercial gain

- You may freely distribute the URL identifying the publication in the public portal 


\title{
Characterization of NMC Lithium-ion Battery Degradation for Improved Online State Estimation
}

\author{
Malthe Thingvad $^{1}$, Lisa Calearo ${ }^{1}$, Andreas Thingvad ${ }^{1}$, Rasmus Viskinde $^{2}$ and Mattia Marinelli ${ }^{1}$ \\ ${ }^{1}$ Department of Electrical Engineering \\ Technical University of Denmark (DTU) \\ Ris $\varnothing$ campus, Roskilde, Denmark \\ s164835@student.dtu.dk, \{lica,athing,matm\}@elektro.dtu.dk \\ ${ }^{2}$ Test Department \\ Lithium Balance A/S \\ Smørum, Denmark \\ rve@lithiumbalance.com
}

\begin{abstract}
This paper presents a characterization of Nickel Manganese Cobalt (NMC) Lithium-Ion (Li-ion) batteries based on empirical tests to improve online state estimation. It investigates how battery degradation affects the battery management systems (BMS) ability to estimate the state of charge (SOC) and state of health (SOH). The testing is conducted on 8 NMC 18650 Li-ion battery cells split up in two groups of four new and four degraded cells with an SOH of $90 \%$.

As both the SOC and the SOH estimations are dependent on the relation between the SOC and the open circuit voltage $(\mathrm{OCV})$, the necessary relaxation time to achieve a stable $\mathrm{OCV}$ as well as the SOC-OCV relations dependency on temperature and ageing are derived. The relaxation time needed to achieve a stabilised terminal voltage is, in the worst case, found to be equal to 20 minutes for both the new and the degraded cells. The SOC-OCV curve is not changing significantly when the operation temperature is increased from $23^{\circ} \mathbf{C}$ to $45^{\circ} \mathbf{C}$, which is also the case for both the new and the degraded cells.

The internal battery resistance and capacitance are however found to depend significantly on both the SOC and operation temperature. A first order $\mathrm{RC}$ representation is derived for different SOC and temperatures levels.
\end{abstract}

Index Terms-Battery Management System, Lithium-ion battery cell, Online estimation, State of Charge, State of Health

\section{INTRODUCTION}

Lithium-ion (Li-ion) batteries are playing an increasingly significant role in powering and enabling modern electronic devices; from smaller batteries powering mobile phones, to electric vehicles (EVs) and large scale grid connected energy storage systems supporting the power system [1].

As the usage increases, it becomes more important that the battery management system (BMS) can accurately estimate the battery's core parameters, to maximise both safety and performance. The most essential parameters for the BMS are the state of charge (SOC) and the state of health (SOH) [2].

This paper seeks to find a characterization of the relevant parameters used in the $\mathrm{SOC}$ and $\mathrm{SOH}$ estimation, primarily the SOC-OCV relation and the energy capacity. The motivation is to find the influence the operating conditions of the battery

The work in this paper has been supported by the research projects ACES (EUDP grant nr: EUDP17-I-12499).

All tests were carried out at Lithium Balance A/S, which actively collaborated with knowledge, equipment availability and cells provision. have on the $\mathrm{SOH}$ estimation. Here the focus being on online estimation [3, 4]. By finding a precise characterization, it is possible to estimate during different operating conditions, and compare the found SOC and $\mathrm{SOH}[5]$.

A precise characterization is also fundamental in making accurate models of the batteries. Modelling can be used to quantify and predict battery behavior, such as the degradation, which is an important aspect in utilizing batteries $[6,7]$.

This paper finds the characterization of $8 \mathrm{Li}-\mathrm{Ion}$ cells. The considered cells are Lithium Nickel Manganese Cobalt (NMC). This chemistry is chosen for the study as it is characterised by a high specific energy and specific power capacity, and therefore it is a very common cell used in both small battery systems and big battery packs as for example EV [8-10].

The paper is organized as follows. Section II provides the theoretical battery characterization and the test method of which the different tests are carried out. Section III presents the characterization of the battery cells. Finally Sections IV concludes the paper with the main outcomes.

\section{Methodology}

This paper investigates the relevant parameters used in the $\mathrm{SOC}$ and the SOH estimation. The SOC shows the remaining charge in the battery, while the $\mathrm{SOH}$ can refer to either a loss of charge capacity or an increase in the internal resistance [11]. In this case the $\mathrm{SOH}$ refers to the loss of charge capacity while the internal resistance is characterised separately for modelling purposes.

The BMS can only measure the voltage, current and temperature of each cell, but this can be used to derive the internal resistance and capacitance, the $\mathrm{SOC}$ and the $\mathrm{SOH}$ [12]. As the open-circuit-voltage (OCV) is a function of the $\mathrm{SOC}$, it is necessary to know the OCV, to get a SOC estimate. The $\mathrm{SOH}$ is conventionally found by doing full charge and discharge cycles, to find the loss of capacity. For several battery applications this is not a viable method, as the battery rarely goes through a full discharge cycle. The $\mathrm{SOH}$ can instead be derived by performing partial discharges, comparing the amount of discharged energy with the resulting variation of SOC. As both the SOC and the SOH estimations are based on 
the SOC-OCV, they are dependent on having a accurate OCV measurement, as well as accurate SOC-OCV relation defined. As the energy capacity, as well as the SOC-OCV relation and the internal resistance and capacitance are dependent on the batteries operating conditions, it is only possible to compare measurements performed under the same conditions. That is problematic as the $\mathrm{SOH}$ often is determined based on a moving average of similar measurements, so the number of usable measurements affects the time it takes to detect a change in the $\mathrm{SOH}$.

The following conditions of the battery are investigated:

- C-rate

- Temperature

- SOC level

- Degradation

\section{A. Battery Theoretical Characterization}

1) SOC and SOH evaluation: The only measurable quantities of the battery cells are the terminal voltage and current, which can be used to derive the characterization of the battery. By integrating the current $(I)$ on time, the capacity in $A h$ can be determined, and it can be used to estimate the SOC and the SOH. SOC is defined in (1) as the specific charge in Ah, $Q_{A h}$, relative to the total capacity, $Q_{A h, f u l l}$, in Ah [11]. $Q_{A h}$ is calculated as in (6):

$$
S O C=\frac{Q_{\mathrm{Ah}}}{Q_{A h, \text { full }}}
$$

The SOC of the cell is not a directly measurable quantity, but it is generally estimated via a combination of different methods. As the SOC of the cells is a function of the voltage, the SOC can be found by measuring the terminal voltage and comparing it to the SOC-OCV curve. The SOC-OCV relation has a slight dependence on temperature, which can be described by the Nernst equation [11] shown in (2):

$$
E=E^{0}-\frac{R T}{z F} \cdot \ln (Q)
$$

where $E$ is the cell voltage potential, $E^{0}$ is the standard cell voltage potential, $R$ is the universal gas constant, $T$ is the temperature in kelvins, $F$ is the Faraday constant, $z$ is the number of electrons transferred in the cell reaction and $Q$ is the reaction quotient of the cell reaction.

It takes some time before the battery voltage settles after the current is stopped, so it is necessary to determine the relaxation time it takes before the terminal voltage is stabilized and equal to the OCV. Since battery applications often are used for extensive periods without breaks, it is necessary to be able to track the trajectory of the SOC during operation. That is done with the method called Coulomb counting, where the current in and out of the battery is measured and integrated, see (1). The accuracy of this method depends on the precision of the current measurement and if it is measured over a long period, the error will accumulate, causing an increasingly significant inaccuracy. It is therefore necessary to calibrate the SOC estimate based on the SOC-OCV curve as often as the operation allows it.
Since the definition of SOC is based on the full capacity it is important to continuously estimate the capacity as it is decreasing due to battery degradation. $\mathrm{SOH}$ is defined in (3), as the full capacity of the cell at time $t\left(Q_{f u l l}\right)$ compared to the nominal capacity, $\left(Q_{\text {nominal }}\right)[11]$ :

$$
S O H=\frac{Q_{\text {full }}}{Q_{\text {nominal }}}
$$

In a laboratory setting, this is measured during a full discharge cycle $100-0 \%$, but for battery applications that rarely go through a full discharge, the estimation can be done by performing two SOC-OCV estimations with an intermediate partial discharge. The $\mathrm{SOH}$ is determined by comparing the change in SOC ( $\left.\triangle S O C_{\mathrm{OCV}}\right)$, found by the two SOC-OCV estimations, to the change in $\operatorname{SOC}\left(\triangle S O C_{\mathrm{CC}}\right)$, found by coulomb counting. This is shown in (4):

$$
S O H_{\mathrm{est}}=\frac{\Delta S O C_{\mathrm{CC}}}{\Delta S O C_{\mathrm{OCV}}} \cdot 100
$$

The SOH can also be derived with incremental capacity analysis (ICA). With ICA the derivative of the capacity $Q$ with respect to the derivative of the voltage $v$ is plotted as a function of the voltage. ICA is defined as $f(v)=\frac{d Q}{d v}[A h / V]$ [13].

As the battery experiences degradation, the peaks of the $(\mathrm{IC}, \mathrm{V})$ curve will change. It can then be compared to other ICA analysed cells with known $\mathrm{SOH}$, and thereby the $\mathrm{SOH}$ of the battery can be derived [14].

2) Capacity evaluation: The full capacity, $Q_{\text {full }}$, can be determined either as the $\mathrm{Ah}$ or Wh capacity. At different temperatures a characterization of the Ah and Wh dependency on the temperature can be derived. For a time resolution of $t_{s}=1 \mathrm{~s}$ and $\Delta T=3600 \mathrm{~s} / \mathrm{h}$ the $\mathrm{Ah}$ and Wh capacity can be calculated as follows:

$$
\begin{aligned}
Q_{\mathrm{Ah}} & =\frac{1}{\Delta T} \sum_{k=0}^{\Delta T} I_{k} \cdot t_{s} \\
Q_{\mathrm{Wh}} & =\frac{1}{\Delta T} \sum_{k=0}^{\Delta T} I_{k} \cdot V_{k} \cdot t_{s}
\end{aligned}
$$

The Wh capacity is not only dependent on the temperature, but also the power due to the voltage drop over the internal resistance.

3) Electrical circuit evaluation: A battery cell can be represented with a Thevenin equivalent as an ideal voltage source in series with a resistance, $R_{s}$, and a RC coupling, $R_{p}$ and $C_{p}$, see Fig. II-A3. $R_{s}$ represents the pure ohmic voltage drop under load conditions, and the RC coupling represents the transient behavior of the battery when the current is stopped.

$R_{s}$ is found by comparing the terminal voltage $V_{T}$ under load conditions $\left(V_{T, \text { Load }}\right)$ to the terminal voltage a second after the current is stopped and the instantaneous voltage drop ( $V_{T, N o \_L o a d}$ has occurred). $R_{p}$ is found by comparing the voltage once the current is stopped $\left(V_{\mathrm{T}, \mathrm{t} 1}\right)$, to the voltage once 


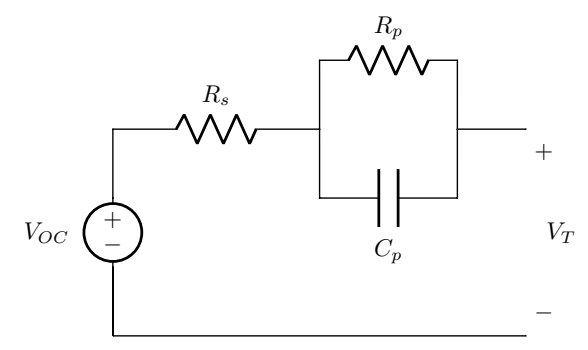

Fig. 1. Thévenin equivalent as an ideal voltage source in series with a resistance and a RC pair.

the cell have relaxed $\left(V_{\mathrm{T}, \mathrm{t} 2}\right)$. The formula for $R_{s}$ and $R_{p}$ can be seen on (7) and (8) [11].

$$
\begin{gathered}
R_{s}=\frac{V_{T, \text { Load }}-V_{T, N o \_l o a d}}{I} \\
R_{p}=\frac{V_{\mathrm{T}, \mathrm{t} 1}-V_{\mathrm{T}, \mathrm{t} 2}}{I_{t, \text { load }}}
\end{gathered}
$$

Because of the reactive components of the RC coupling the system experience a time delay from the current is stopped where the capacitor is gradually discharged [15]. It takes three times the time constant $\tau$ to lose $95 \%$ of the capacitor charge. The relationship between $\tau$ and the values of $R_{p}$ and $C_{p}$ can be seen in (9).

$$
\tau=R_{p} \cdot C_{p}
$$

\section{B. Test Setup}

1) Battery characterization: The described tests are conducted on 8 INR18650-30Q NMC battery cells produced by Samsung SDI. Four fresh cells, and four degraded cells with $\approx 90 \%$ SOH were used. It is unknown how long time has passed since production of the unused cells. The degraded cells are chosen to have a similar capacity of $90 \%$ based on a measurement of a full discharge. The rest of the paper will refer to the fresh cells as Set A and the degraded cells as Set $B$. The nameplate specifications of the cells are listed in Table II-B1.

TABLE I

SPECIFICATION OF INR18650-30Q CELLS.

\begin{tabular}{|c|c|}
\hline Item & Specification \\
\hline Nominal discharge capacity & $2.950 \mathrm{Ah}$ \\
\hline Nominal voltage & $3.6 \mathrm{~V}$ \\
\hline Minimum voltage & $2.5 \mathrm{~V}$ \\
\hline Maximum voltage & $4.2 \mathrm{~V}$ \\
\hline
\end{tabular}

2) Experiment setup: Initial testing was executed to determine the constant current (CC) discharge capacity of the cells. The cells Ah capacity and the equivalent $\mathrm{SOH}$, calculated based on the rated capacity, can be seen in Table II. All tests were performed using a test setup consisting of a "CADEX C8000 Battery testing system," a "CTS C-70/350" Climate Chamber, and a PC running the control software. The CADEX battery tester has a voltage accuracy of $0.1 \%$ and a current accuracy of $0.25 \%$ full scale, with a sample rate of 1 second
TABLE II

1C CC DISCHARGE CAPACITY AT $23^{\circ} \mathrm{C}$ AND SOH OF CELLS.

\begin{tabular}{|c|c|c|}
\hline Cell & Discharge capacity $[\mathrm{Ah}]$ & SOH \\
\hline A1 & 2.89 & 96.33 \\
A2 & 2.92 & 97.33 \\
A3 & 2.88 & 96.00 \\
A4 & 2.90 & 96.66 \\
\hline B1 & 2.73 & 90.90 \\
B2 & 2.72 & 90.77 \\
B3 & 2.72 & 90.93 \\
B4 & 2.72 & 90.70 \\
\hline
\end{tabular}

[16]. The climate chamber has a temperature range of $-40^{\circ} \mathrm{C}$ to $+180^{\circ} \mathrm{C}$, and a humidity range between $10 \%$ and $98 \% \mathrm{rH}$ [17]. The battery cells are connected to the battery tester via a copper clad PCB board, with one cell per channel, so the current can be controlled individually. The plus and minus terminals are connected to the cathode and anode, and the temperature sensors are connected to either side of each cell.

A block diagram of the entire setup can be seen in Fig. 2.

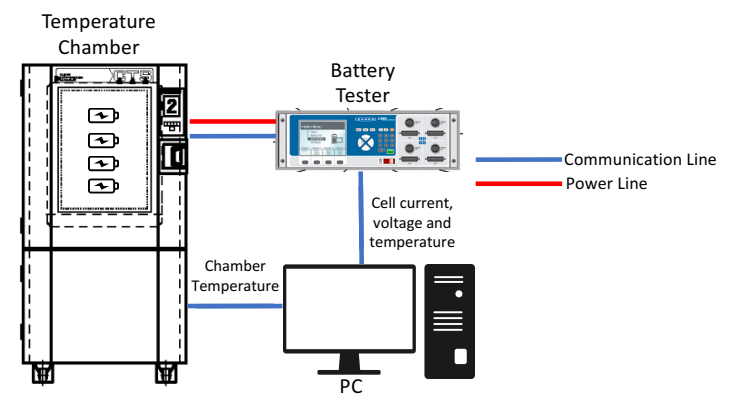

Fig. 2. Test setup.

The cells are placed in the temperature controlled chamber at the chosen test temperature for a minimum of 12 hours before the test to get a stabilised temperature. The humidity is kept at $60 \%$ to follow the standard test conditions of the INR18650-30Q data sheet. The test conditions for the cells are a charge/discharge rate of $1 \mathrm{C}$ and a temperature of $23^{\circ} \mathrm{C}$. Only one parameter is changed for each test. All tests start with the cells being charged with constant current constant voltage $(\mathrm{CCCV})$ followed by a 20 min relaxation time. This is done to ensure that the test is done at the same voltage baseline. The tests are conducted with 4 at the time on 4 isolated channels, with individual power profiles as well as voltage and current measurements, where each cells voltages, current and temperature is logged per second.

All tests were carried out at Lithium Balance A/S, experts in the field of batteries and BMS.

\section{Test Profiles}

The tests can be divided in three main categories depending on the test profiles and objectives.

Test A: The cells are completely discharged at $5^{\circ} \mathrm{C}$ with a C-rate of 0.5 and then given $60 \mathrm{~min}$ relaxation where the voltage increase is logged. The test is repeated with a C-rate and $1 \mathrm{C}$ and $2 \mathrm{C}$. 
The test objective is to find the impact the C-rate has on the relaxation time of the battery, and to derive the necessary relaxation time for a sufficiently accurate OCV measurement. The relaxation time is found at $5^{\circ} \mathrm{C}$ and after a full discharge to test it in the worst case scenario.

Test B: The cells are charged and discharged with CCCV at $1 \mathrm{C}$, between 2.5 and $4.2 \mathrm{~V}$, with an intermediate 20 min rest period. Generally discharge tests are made only with $\mathrm{CC}$ but since charging tests generally is made with CCCV, it is used to be able to compare the charge and discharge capacity. The test is done at $5^{\circ} \mathrm{C}, 23^{\circ} \mathrm{C}$, and $45^{\circ} \mathrm{C}$.

The test objective is to find the influence the temperature has on the cell charge and discharge capacity.

Test C: The cells are discharged with $\mathrm{CC}$ at $1 \mathrm{C}$. The cells are discharged with steps of $0.3 \mathrm{Ah}$ and a subsequent 20 min rest period until it reaches the minimum cell voltage. The cells are tested at $23^{\circ} \mathrm{C}$ and $45^{\circ} \mathrm{C}$

The test objective is to determine the influence temperature have on the SOC-OCV curve and to find the internal resistance and capacitance at different SOC levels, as well as doing the ICA.

\section{RESULTS}

\section{A. Relaxation time}

From test $\mathrm{A}$ the impact the $\mathrm{C}$-rate has on the relaxation time is derived as comparison between differential of the voltage per 5 minute after the current is stopped and the time. The result is shown in Fig. 3 for set A and set B respectively.
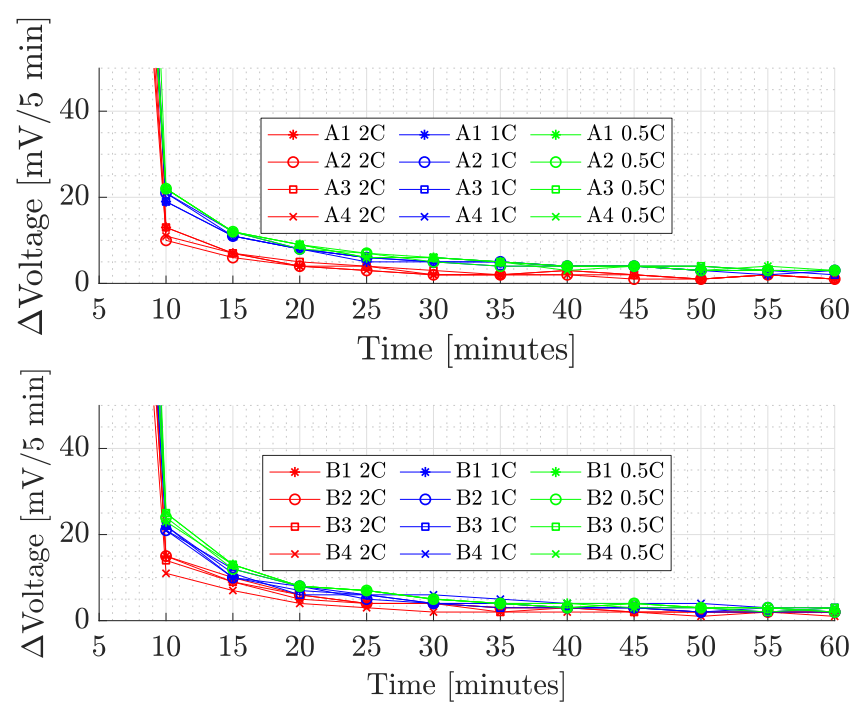

Fig. 3. Voltage difference per minute at $5^{\circ} \mathrm{C}$.

The relaxation time for both set $\mathrm{A}$ and set $\mathrm{B}$ is observed to be only dependent on the C-rate, to a limited extent. Even though the $\mathrm{C}$-rate has a big influence on the terminal voltage and the discharge process, the terminal voltage is still fully stabilised $20 \mathrm{~min}$ after the current is cut off. It can also be observed that the necessary relaxation time for the OCV to stabilise does not increase as the cells age. After 20 minutes both set $\mathrm{A}$ and $\mathrm{B}$ have a per 5 minute change of less than 10 $\mathrm{mV}$.

\section{B. Capacity}

The results are derived from test $\mathrm{B}$. Because of a problem with the measurement of cell number 2 , there are no results for $A 2$ and $B 2$ in this section.

1) Ah: In Fig. 4 the Ah charge and discharge capacity for set A and B can be seen. For set A both charge and discharge capacity increases as the temperature increases and the difference between charge and discharge capacity decreases. At $45^{\circ} \mathrm{C}$ the difference is very limited. The same behaviour can be seen for set B, but the difference between charge and discharge capacity has a significantly increase at $5^{\circ} \mathrm{C}$ and at $23^{\circ} \mathrm{C}$. At $45^{\circ} \mathrm{C}$ the difference is still very limited.
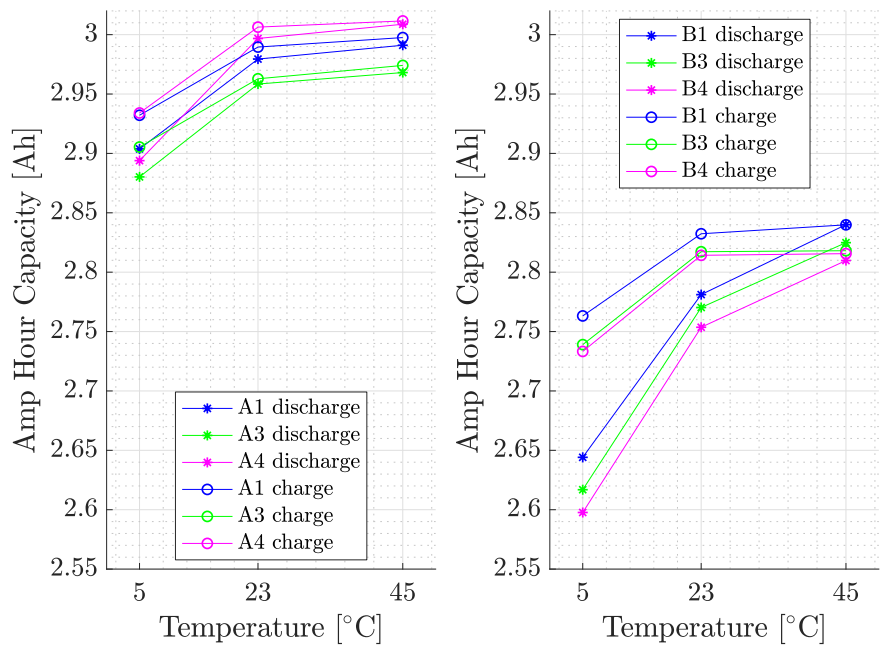

Fig. 4. Amp hour charge and discharge capacity at different temperatures.

On average for set $\mathrm{A}$ the $\mathrm{Ah}$ discharge capacity changes $2.87 \%$ from $23^{\circ} \mathrm{C}$ to $5^{\circ} \mathrm{C}$, and $0.37 \%$ from $23^{\circ} \mathrm{C}$ to $45^{\circ} \mathrm{C}$. For set $\mathrm{B}$ the $\mathrm{Ah}$ discharge capacity changes $5.38 \%$ from $23^{\circ} \mathrm{C}$ to $5^{\circ} \mathrm{C}$, and $2.00 \%$ from $23^{\circ} \mathrm{C}$ to $45^{\circ} \mathrm{C}$.

There is a difference between the charge and discharge capacity but the discharge capacity can be estimated based on the charge capacity by accounting for the effect of the $\mathrm{SOH}$ and the temperature. The found capacities are larger than the ones reported in Table II where the measurements are made with $\mathrm{CCCV}$ and not $\mathrm{CC}$.

2) Wh: Fig. 5 shows the Wh charge and discharge capacity. There is a significantly larger difference between the charge and discharge capacity when calculating the Wh capacity instead of the Ah capacity. This is caused by the voltage drop over the internal resistance. This also explains the increased difference between set A and set B as the internal resistance is increased for the degraded cells. For both sets the difference between charge and discharge capacity is reduced as the temperature increases and the internal resistance decreases with the temperature. On average for set $\mathrm{A}$ the $\mathrm{Wh}$ discharge capacity changes $3.93 \%$ from $23^{\circ} \mathrm{C}$ to $5^{\circ} \mathrm{C}$, and $1.73 \%$ from 

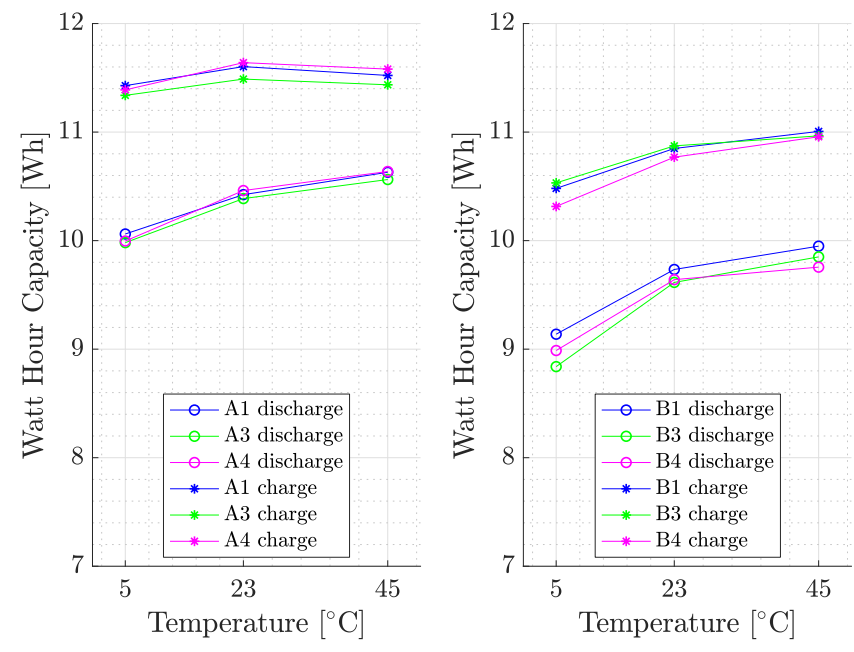

Fig. 5. Watt hour charge and discharge capacity at different temperatures.

$23^{\circ} \mathrm{C}$ to $45^{\circ} \mathrm{C}$. For set $\mathrm{B}$ the Wh discharge capacity changes $7.04 \%$ from $5^{\circ} \mathrm{C}$ to $23^{\circ} \mathrm{C}$, and $1.90 \%$ from $23^{\circ} \mathrm{C}$ to $45^{\circ} \mathrm{C}$.

\section{Thévenin equivalent parameters}

The Thévenin equivalent seen in Fig. II-A3, consists of an internal resistance, $R_{s}$, in series with a parallel coupled resistance, $R_{p}$, and capacitance, $C_{p}$. The values for each are derived from test $\mathrm{C}$ so there is a resulting internal resistance, parallel capacitance and OCV for every $10 \%$ SOC step.

1) $R_{s}$ : In Fig. $6 R_{s}$ is shown for set $\mathrm{A}$ and $\mathrm{B}$ at different temperatures and SOC levels.
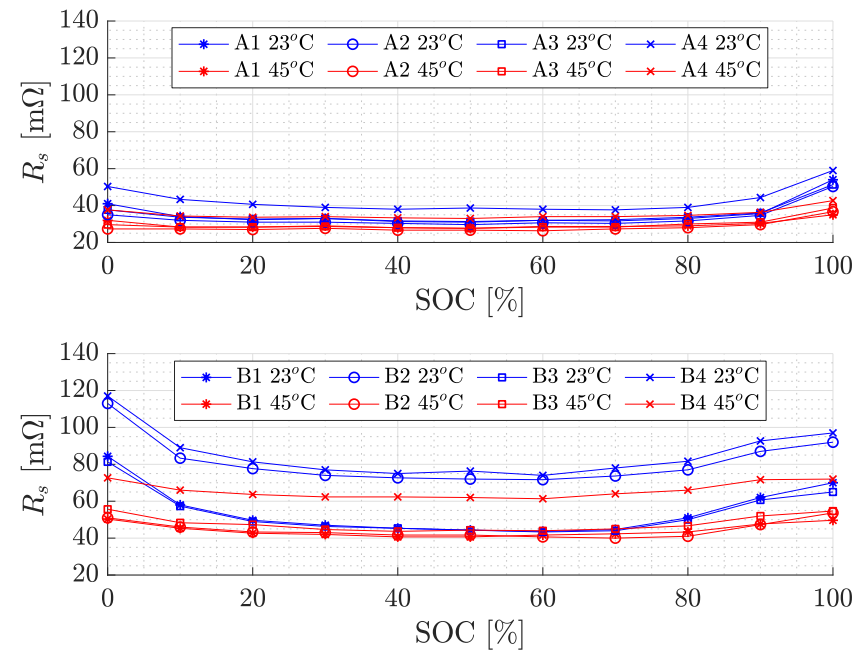

Fig. 6. Series Resistance.

The cells in set $\mathrm{B}$ have an increased $R_{s}$, compared to set $\mathrm{A}$, as the cells have aged. $R_{s}$ is lower at $45^{\circ} \mathrm{C}$ than at $23^{\circ} \mathrm{C}$ for each SOC point for each cell in both sets. For set $\mathrm{A} R_{s}$ varies by a small amount between $10 \%$ and $90 \%$ SOC, but is increased when the battery is close to being fully charged or discharged. For set $\mathrm{B} R_{s}$ varies significantly more and starts increasing when outside the range $30-70 \%$ SOC.
2) $R_{p}$ : In Fig. $6 R_{p}$ is shown for set $\mathrm{A}$ and $\mathrm{B}$ at different temperatures and SOC levels. $R_{p}$ is stable for SOC above
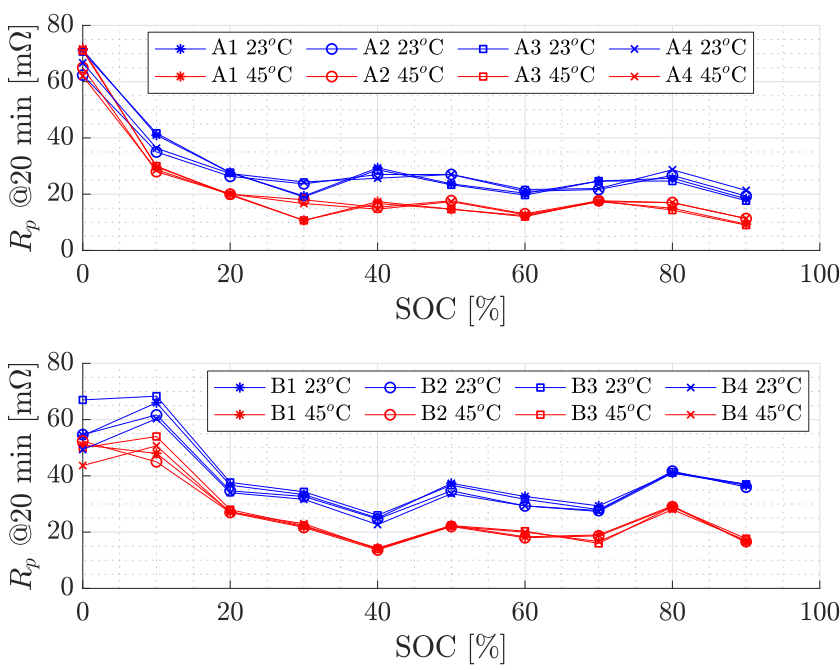

Fig. 7. Parallel Resistance.

$25 \%$ and below it increases to almost a double from 25 to $0 \%$ SOC. $R_{p}$ is also lower at higher temperatures, behaviour that is observed for both sets of cells at every SOC point.

3) $C_{p}$ : In Fig. $8 C_{p}$ is shown for set $\mathrm{A}$ and $\mathrm{B}$ at $23^{\circ} \mathrm{C}$.
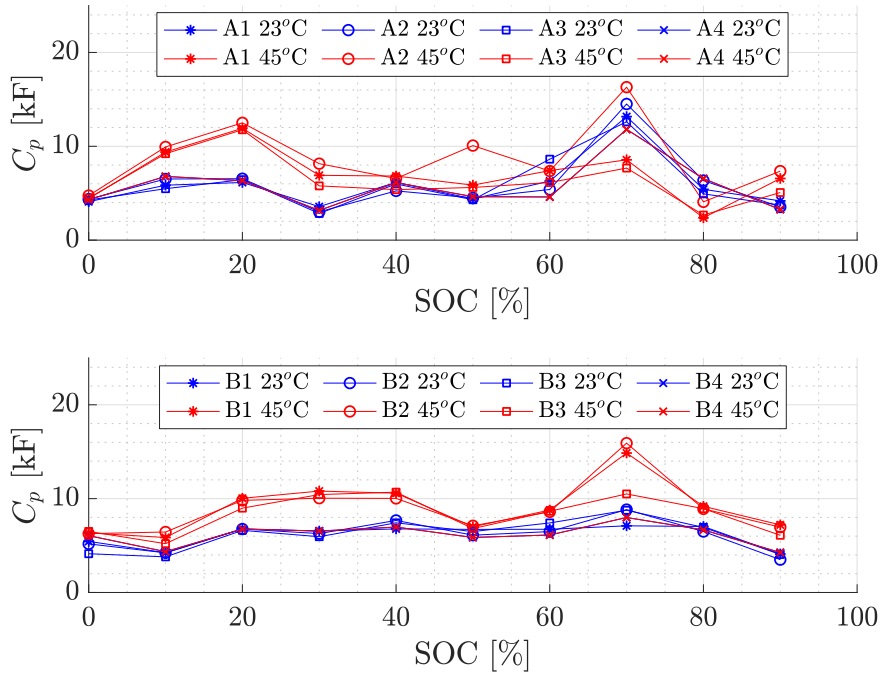

Fig. 8. Parallel Capacitance for set A and set B.

\section{SOC-OCV relation}

In Fig. 9 the SOC-OCV curves for set $\mathrm{A}$ at $23^{\circ} \mathrm{C}$ and $45^{\circ} \mathrm{C}$ and set $\mathrm{B}$ at $23^{\circ} \mathrm{C}$ and $45^{\circ} \mathrm{C}$ are derived. For set $\mathrm{A}$ there is a max difference of $2.00 \%$, and for set $\mathrm{B}$ there is a max difference of $3.64 \%$ between the SOC-OCV curve at $23^{\circ} \mathrm{C}$ and $45^{\circ} \mathrm{C}$. There is a max difference of $1.99 \%$ between the cells in set A and the cells in set B at low SOC. The difference is highest at low SOC. 

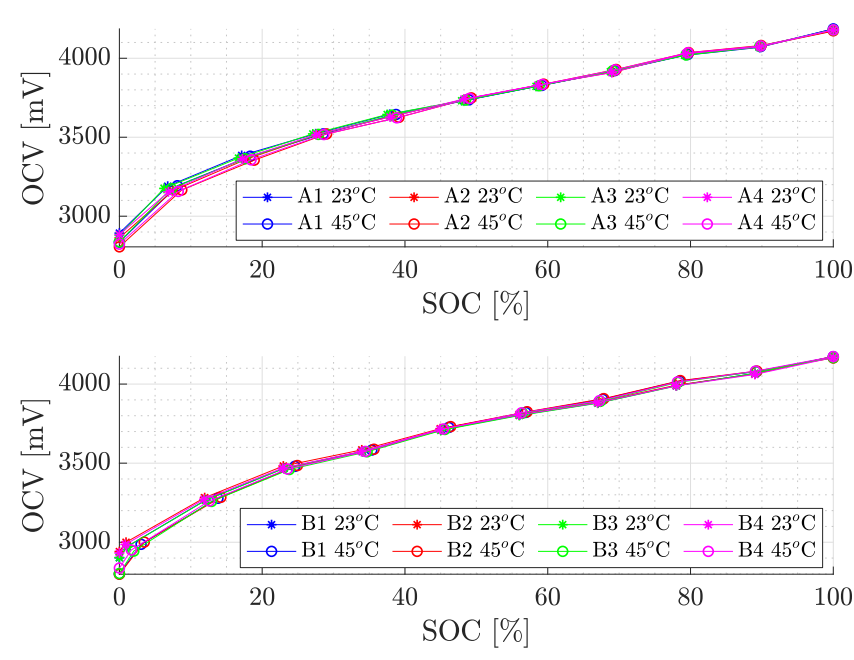

Fig. 9. SOC-OCV curve for Set A and set B.

\section{E. Incremental Capacity}

In Fig. 10 the IC plot for set A and B is derived. The ICA is plotted as a function of the SOC. The curve for all the cells

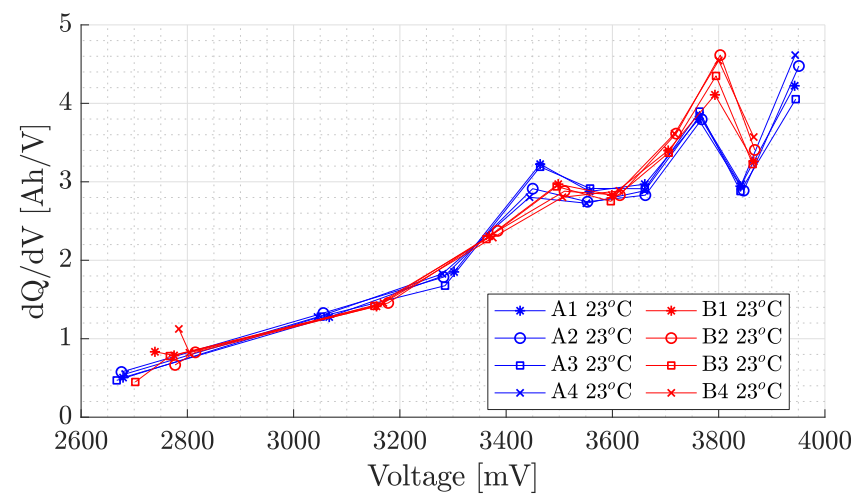

Fig. 10. ICA plot with respect to voltage for both sets A and B.

in set A are very similar but as well as the curves for the cells in set $\mathrm{B}$ but when comparing the two sets it is clear that the peaks of set $B$ are moved to the right. That indicates that there is a relation between the ICA peaks and the SOH. If ICA is made for large quantities of cells with a range of $\mathrm{SOH}$ it could potentially be used to benchmark $\mathrm{SOH}$ as also found by [13].

\section{CONCLUSion AND Future Works}

This paper has derived the characterization of eight Li-ion NMC cells, four fresh and four aged, both theoretically and experimentally, considering a controlled test environment based on an online parameter estimation.

The necessary relaxation time for the OCV to stabilise at different $\mathrm{C}$-rates was tested. It was found that both $\mathrm{C}$-rate and degradation level of the battery cells had minimal influence, and that a relaxation time of $20 \mathrm{~min}$ is enough for an accurate OCV estimate.

The relation between the charge and discharge capacity is found to depend on the $\mathrm{SOH}$ and the temperature. When going from $\mathrm{Wh}$ to $\mathrm{Ah}$, there is a significantly larger difference between the charge and discharge capacity, but that can also be estimated when knowing the internal resistance.

The equivalent $R_{s}, R_{p}$ and $C_{p}$ of the Thévenin equivalent model were presented, showing similar behaviour, but different values for the aged and the new cells.

The SOC-OCV relation was found to be very similar for set $\mathrm{A}$ and $\mathrm{B}$ at $23^{\circ} \mathrm{C}$ and $45^{\circ} \mathrm{C}$. A small temperature dependence was observed between $23^{\circ} \mathrm{C}$ and $45^{\circ} \mathrm{C}$ at low SOC.

An ICA was made for the fresh and the degraded cells. It was shown that cells with different $\mathrm{SOH}$ also have different ICA characteristics but further analysis are required to be able to find the SOH based on the ICA.

Due to the large field of applications of the Li-ion batteries further investigations could consider other temperatures and conditions to characterize the cells on further situations. Further cells should also be considered to validate the results on a larger scale. The Thévenin parameters were found during discharging but could also be found during charging conditions, to derive a potential change in battery parameters when comparing charge and discharge processes.

Furthermore it can be investigated how precisely the SOC and $\mathrm{SOH}$ can be estimated in different scenarios using the found characterization, and how precisely $\mathrm{SOC}$ and $\mathrm{SOH}$ of the aged cells can be estimated using the characterization of the fresh cells.

\section{REFERENCES}

[1] A. Thingvad, C. Ziras, and M. Marinelli, "Economic value of electric vehicle reserve provision in the nordic countries under driving requirements and charger losses," Journal of Energy Storage, vol. 21, pp. 826-834, 2019.

[2] K. Prasad and B. Divakar, "Real time estimation of soc and soh of batteries," International Journal of Renewable Energy Research, vol. 8, pp. 44-55, 012018

[3] M. Einhorn, F. V. Conte, C. Kral, and J. Fleig, "A method for online capacity estimation of lithium ion battery cells using the state of charge and the transferred charge," Industry Applications, IEEE Transactions on, vol. 48, 122010.

[4] E. Schaltz, D.-I. Stroe, K. Nørregaard, B. Johnsen, and A. Christensen, "Partial charging method for lithium-ion battery state-of-health estimation," in Proceedings of 2019 Fourteenth International Conference on Ecological Vehicles and Renewable Energies (EVER). IEEE Press, May 2019.

[5] M. Thingvad, "Online state of health estimation of lithium ion batteries," Diplom Thesis in Electrical Engineering, DTU, Jan. 2020.

[6] A. Baczyńska, W. Niewiadomski, A. Gonçalves, P. Almeida, and R. Luís, "Li-nmc batteries model evaluation with experimental data for electric vehicle application," Batteries, vol. 4, p. 11, 022018.

[7] A. Thingvad and M. Marinelli, "Influence of v2g frequency services and driving on electric vehicles battery degradation in the nordic countries," in EVS31, 2018.

[8] D. Li J. Wang T. Qin, "Analysis of the current electric battery models for electric vehicle simulation," Automotive Innovation, 169:826 - 834, 2019.

[9] L. Calearo, A. Thingvad, and M. Marinelli, "Modeling of battery electric vehicles for degradation studies," in Proceedings of the 54th International Universities Power Engineering Conference, 2019.

[10] Y. Miao, P. Hynan, A. von Jouanne, and A. Yokochi, "Current li-ion battery technologies in electric vehicles and opportunities for advancements," Energies, vol. 12, pp. 1074-1094, 032019.

[11] D. Linden, Lindens handbook of batteries. McGraw-Hill, 2008.

[12] P. Weicker, A systems approach to lithium-ion battery management. Artech House, 2014.

[13] X. Gong, "Modeling of lithium-ion battery considering temperature and aging uncertainties," 2016.

[14] E. Schaltz, D.-I. Stroe, K. Nørregaard, L. Stenhøj Kofod, and A. Christensen, "Incremental capacity analysis for electric vehicle battery state-of-health estimation," in Proceedings of 2019 Fourteenth International Conference on Ecological Vehicles and Renewable Energies (EVER). IEEE Press, 2019.

[15] F. Baccino, M. Marinelli, P. Nørgård, and F. Silvestro, "Experimental testing procedures and dynamic model validation for vanadium redox flow battery storage system," Journal of Power Sources, vol. 254, pp. 277-286, 2013.

[16] C. E. Inc, "C8000 battery testing system," 2019.

[17] C. ApS, "Cts c-70/350 klimaskab," 2019. [Online]. Available: https://www.citrotek.dk/udlejning-brugt 